\title{
Metastatic Well Differentiated Neuroendocrine Neoplasm
}

National Cancer Institute

\section{Source}

National Cancer Institute. Metastatic Well Differentiated Neuroendocrine Neoplasm. NCI Thesaurus. Code C147065.

A well differentiated neuroendocrine neoplasm that has spread from the original site of growth to another anatomic site. 